\title{
Improvement of the Ti-6Al-4V Alloy's Tribological Properties and Electrochemical Corrosion Resistance by Nanocomposite TiN/PEEK708 Coatings
}

\author{
TOMASZ MOSKALEWICZ, MACIEJ WARCABA, SŁAWOMIR ZIMOWSKI, \\ and ALICJA ŁUKASZCZYK
}

\begin{abstract}
In this work, polyetheretherketone-based TiN/PEEK 708 nanocomposite coatings on oxygen hardened Ti-6Al-4V titanium alloy substrates were fabricated by using cathodic electrophoretic deposition and post-heat treatment. The microstructure of coatings was investigated by using scanning electron microscopy, transmission electron microscopy, and X-ray diffractometry. The scratch resistance, tribological properties, and electrochemical corrosion resistance were also studied. The results show that homogeneous TiN/PEEK708 coatings may be deposited from ethanol-based suspensions containing cationic chitosan polyelectrolyte, which provides electrosteric stabilization of the suspension. Heat treatment densified the coatings and changed the PEEK structure from amorphous to semi-crystalline. The coatings were characterized by very good scratch resistance, with no cohesive and adhesive cracks being observed up to the load of $30 \mathrm{~N}$. They reduced the coefficient of friction from 0.70 for the baseline alloy and 0.65 for the oxygen hardened alloy to 0.30 . They also significantly increased the wear resistance of the alloy during dry sliding contact with an alumina ball. The wear rate of the coated oxygen hardened alloy was about 70 and 650 times lower in comparison with the oxygen hardened and baseline alloy, respectively. The corrosion studies demonstrated that the baseline and oxygen hardened alloy have comparable corrosion resistance. The TiN/PEEK708 coating enhanced the electrochemical corrosion resistance of the alloy in the $\mathrm{NaCl}$ aqueous solution.
\end{abstract}

https://doi.org/10.1007/s11661-019-05484-7

(C) The Author(s) 2019

\section{INTRODUCTION}

TITANIUM and its alloys have excellent properties, such as low density, high specific strength, good electrochemical corrosion resistance, relatively low elasticity modulus, and good biocompatibility. They are often used as structural components in the aerospace, automotive, petrochemical, and marine industries, as well as in chemical and biomedical engineering. ${ }^{[1,2]}$ Among titanium alloys, the two-phase $(\alpha+\beta)$ Ti-6Al-4V alloy is most widely used as a

TOMASZ MOSKALEWICZ and MACIEJ WARCABA are with the Faculty of Metals Engineering and Industrial Computer Science, AGH University of Science and Technology, Czarnowiejska 66, 30-054 Kraków, Poland. Contact e-mail: tmoskale@agh.edu.pl. SEAWOMIR ZIMOWSKI is with the Faculty of Mechanical Engineering and Robotics, AGH University of Science and Technology, Mickiewicza Av. 30, 30-059 Kraków, Poland. ALICJA ŁUKASZCZYK is with the Faculty of Foundry Engineering, AGH University of Science and Technology, 30-059 Kraków, Poland Manuscript submitted June 28, 2019.

Article published online October 10, 2019 general-purpose alloy. Its high applicability results from a good balance of mechanical properties and good cast ability, plastic workability, heat treatability, and weldability. ${ }^{[3]}$ The major disadvantages of all titanium alloys, including this alloy, especially in applications exposed to friction, are their poor resistance to abrasive wear, high tendency to seize, high coefficient of friction (COF), and relatively low hardness. ${ }^{[4,5]}$

Researchers have focused on improving the tribological properties of titanium alloys by applying different composite coatings or diffusion surface layers. ${ }^{[6-10]}$ In particular, thermoplastic polymer-based coatings hardened with ceramic nanoparticles are of great relevance. ${ }^{[11]}$ Among them, polyetheretherketone (PEEK) is often used as a matrix of composite coatings ${ }^{[11-15]}$ due to its excellent toughness-stiffness combination, high thermal and chemical stability, good tribological performance, and high mechanical strength relative to other thermoplastics. ${ }^{[1,16-19]}$ The PEEK properties originate from the aromatic structure of the polymer chain and its semi-crystalline character, which depends on the thermomechanical processing history. ${ }^{[20]}$ The degree of crystallinity depends on the processing conditions, such 
as cooling rates and annealing treatments. The melting point of PEEK lies in the temperature range of $330^{\circ} \mathrm{C}$ to $385{ }^{\circ} \mathrm{C}$, depending on the relative number of ether ketone linking the phenylene rings. ${ }^{[21]}$ The thermal decomposition of PEEK is about $580{ }^{\circ} \mathrm{C} .{ }^{[17]}$ The good tribological performance of PEEK promotes the development of coatings on titanium alloys, which exhibit poor tribological performance. However, the wear rate of pure PEEK in dry sliding is still not enough for medium and high load-bearing applications. A common method for further improvement of the PEEK properties is reinforcing the polymer with fillers. Different fillers, for example, $\mathrm{SiC},{ }^{[16]}$ graphene nanoplatelets, ${ }^{[20]}$ $\mathrm{h}-\mathrm{BN},{ }^{[22]}$ carbon or glass fibers, ${ }^{[23,24]}$ bioglass, ${ }^{[25,26]}$ or hydroxyapatite (HA), ${ }^{[27]}$ were used in the literature to enhance the PEEK properties, in particular wear resistance, mechanical properties, or osseointegration.

The PEEK and PEEK-based composite coatings were successfully deposited on metallic substrates using thermal spraying and printing techniques. ${ }^{[11,16,17,19,28-31]}$ An alternative effective technique for the deposition of PEEK and PEEK-based coatings is electrophoretic deposition (EPD). ${ }^{[12-15,25-27,32-36]}$ In previous studies of the authors, dense and well-adhered pure PEEK ${ }^{[32]}$ and composite PEEK-based coatings ${ }^{[26,33-36]}$ have been successfully fabricated on titanium alloy substrates by EPD and subsequent heat treatment. Different reinforcing materials were used to enhance the PEEK properties, e.g., nanocrystalline $\mathrm{Al}_{2} \mathrm{O}_{3},{ }^{[34]}$ amorphous $\mathrm{Si}_{3} \mathrm{~N}_{4}$ nanoparticles (NPs), ${ }^{[35]}$ and $\mathrm{MoS}_{2}$ nanosheets. ${ }^{[36]}$ Some inorganic NPs have been demonstrated to have the capability to reduce the friction and wear of PEEK. In particular, $\mathrm{Al}_{2} \mathrm{O}_{3}$ nanoparticle-reinforced PEEK coatings exhibited improved wear resistance in comparison with pure PEEK coatings. ${ }^{\text {[34] }}$

In the case of electrophoretic deposition of PEEKbased coatings reinforced with $\mathrm{Si}_{3} \mathrm{~N}_{4}$ amorphous particles (size up to $50 \mathrm{~nm}$ ) problems were encountered in obtaining homogeneous coatings on the Ti-13Nb-13Zr titanium alloy. Introduction of the cationic polyelectrolytes polyethylenimine and chitosan into an EtOHbased suspension facilitated the deposition of coatings. The most homogeneous coatings were deposited from a suspension containing 50 vol pct of chitosan polyelectrolyte, but they were characterized by relatively high open porosity, due to the degradability of chitosan during post EPD heat treatment. ${ }^{[35]}$

Because of its high hardness, chemical inertness and stability, as well as low COF, TiN NPs are widely used as a particulate-reinforced phase in composites. ${ }^{[37]}$ However, no published article concerning TiN/PEEK nanocomposite coatings can be found in the available literature. In this work, crystalline TiN nanoparticles were used to enhance the tribological properties of PEEK and lower the content of chitosan polyelectrolyte in the suspensions in order to reduce open porosity in the coatings.

The aim of the present work is to elaborate the EPD conditions for the deposition of homogeneous TiN/ PEEK708 nanocomposite coatings on oxygen hardened Ti-6Al-4V titanium alloy and to characterize the coating microstructure and selected properties of the coated alloy, such as scratch resistance of the coating, tribological properties, and electrochemical corrosion resistance in an aqueous $\mathrm{NaCl}$ solution. In particular, the new materials are considered in order to improve the tribological and micro-mechanical performance of titanium alloy, also in comparison with pure PEEK coated alloy.

\section{MATERIAL AND EXPERIMENTAL METHODS}

\section{A. Substrate Material}

A two-phase $(\alpha+\beta)$ Ti-6Al-4V titanium alloy was used as a substrate material for coating deposition. The alloy was delivered in the form of a bar, in hot rolled and annealed condition for 2 hours at $750{ }^{\circ} \mathrm{C}$ by BÖHLER Edelstahl GmbH, Germany. The disk-shaped samples, $22 \mathrm{~mm}$ in diameter and $3 \mathrm{~mm}$ thick, cut from the bar were mirror polished and, finally, diffusion hardened with interstitial oxygen atoms, according to a procedure described elsewhere. ${ }^{[8]}$ Glow discharge plasma thermal oxidation caused grain growth up to $15 \mu \mathrm{m}$ for $\alpha$ phase and up to $5 \mu \mathrm{m}$ for $\beta$ phase, and changes in grain morphology from elongated to equiaxed. The near surface region in the diffusion zone consisted mainly of $\mathrm{Ti} \alpha(\mathrm{O})$ solid solution enriched with oxygen. As a result of such treatment, the surface hardness of the alloy increased threefold, from 3.4 to $10.6 \mathrm{GPa}^{[8]}$ To ensure a similar surface finish, all the diffusion hardened disks were polished with use of a 3 $\mu \mathrm{m}$ diamond paste to a final roughness $\mathrm{Ra} \sim 0.02 \mu \mathrm{m}$.

\section{B. EPD of Coatings}

PEEK708 micro particles (size below $10 \mu \mathrm{m}$, density of $1.32 \mathrm{~g} / \mathrm{cm}^{3}$, melting point of $372{ }^{\circ} \mathrm{C}$ ) and $\mathrm{TiN}$ nanoparticles (average particle size $20 \mathrm{~nm}$, purity $>$ 97 pct, SSA: 40 to $55 \mathrm{~m}^{2} / \mathrm{g}$, morphology: spherical, density: $5.22 \mathrm{~g} / \mathrm{cm}^{3}$ ) were used for coating deposition by EPD. PEEK 708 was delivered by Victrex Europa GmbH, Germany, while the TiN was delivered by Nanostructured \& Amorphous Materials, Inc. (NanoAmor), USA.

Two different suspensions were elaborated for the EPD of composite coatings. The first suspension consisted of PEEK708 (1.50 g) in $50 \mathrm{~mL}$ of ethanol. The second suspension consisted of $1.50 \mathrm{~g}$ of PEEK 708 and $0.02 \mathrm{~g}$ of $\mathrm{TiN}$ in a dispersion medium $(50 \mathrm{~mL})$ composed of ethanol $(37.5 \mathrm{~mL})$ and a colloidal solution of chitosan $(12.5 \mathrm{~mL})$. The medium molecular weight chitosan, with a degree of deacetylation of about 75 to 85 pct, was delivered by Sigma-Aldrich (Poland). Chitosan polyelectrolyte was used as a cationic dispersant. Colloidal solutions of chitosan $(2 \mathrm{~g} / \mathrm{L})$, in a mixture of $50 \mathrm{vol}$ pct of ethanol, $0.5 \mathrm{vol}$ pct of acetic acid, and distilled water, were prepared by magnetic stirring at $300 \mathrm{rpm}$ at room temperature (RT) for 72 hours. Citric acid $\left(\mathrm{C}_{6} \mathrm{H}_{8} \mathrm{O}_{7}\right)$ and sodium hydroxide $(\mathrm{NaOH})$ were used to change the $\mathrm{pH}$ of the suspensions. The $\mathrm{pH}$ was measured using a Mettler Toledo EL20 pH-meter (China). 
Before coating deposition, each suspension was dispersed in an ultrasonic bath for 15 minutes and mixed using a magnetic stirrer for 2 minutes. To elaborate a stable suspension, the electrokinetic properties, zeta potential (ZP), and electrophoretic mobility of both types of particles were measured using a Zetasizer Nano ZS90 (Malvern Instruments Ltd. UK). To avoid multiple scattering, all the samples containing PEEK708 particles in the cuvette were heavily diluted, which made them suitable for electrophoretic light-scattering measurements.

Electrophoretic deposition was carried out in a two-electrode cell. The counter electrode was an AISI316L austenitic stainless steel. The distance between the electrodes in the cell was $10 \mathrm{~mm}$. The constant voltage in the range of 30 to $100 \mathrm{~V}$, with every $10 \mathrm{~V}$, was applied using an EX752M multimode PSU DC power supply, UK. The deposition time was 30, 40, $50,60,70,80$, and 90 seconds. The influence of the applied voltage on current density during the EPD process was investigated using a Tektronix DMM 4040 multimeter (USA). The as-deposited coatings were dried in air at RT and weighed together with the cathodic substrate to determine the deposited weight.

Samples with the as-deposited coatings were heat treated in a Carbolite Gero LHTO 4/30 laboratory oven (UK), at a temperature of $390{ }^{\circ} \mathrm{C}$ for 40 minutes (heating rate of the samples $4.5{ }^{\circ} \mathrm{C} / \mathrm{min}$ ), and were cooled down in a furnace (cooling rate of $2^{\circ} \mathrm{C} / \mathrm{min}$ ) after soaking.

\section{Investigation of Microstructure and Surface Topography}

The microstructure of the powders and coatings was characterized by scanning and transmission electron microscopy (SEM, TEM). The SEM investigation was performed by an FEI Nova NanoSEM 450 (the Netherlands). The TEM investigation was carried out using a JEOL JEM-2010 ARP microscope, Japan. The structure and phase composition were investigated by means of X-ray diffractometry (XRD) and by selected area electron diffraction (SAED). The XRD patterns were recorded using a Panalytical Empyrean DY1061 diffractometer (the Netherlands) applying $\mathrm{Cu}-\mathrm{K} \alpha$ radiation on plan-view specimens. Three types of samples were used for TEM investigation. Thin foils from TiN nanoparticles used for EPD were prepared by dispersing the powder in ethanol and ultrasonic stirring to separate agglomerated nanoparticles. Finally, a droplet of the suspension was placed on the copper grid coated by carbon film and dried. Thin foils from the different suspensions used for EPD were also prepared by placing a droplet of the stable suspension on a carbon film deposited on 300 mesh grids of copper and finally dried. Lamellae from a cross-section of the coatings were prepared by a focus ion beam (FIB) using an FEI QUANTA 3D 200i device (the Netherlands). The chemical composition was analyzed by energy dispersive X-ray spectroscopy (SEM-EDS, TEM-EDS).
The surface topography of the coatings was investigated by atomic force microscopy (AFM). The investigation was performed with use of a Veeco Dimension ${ }^{\circledR}$ Icon $^{T M}$ SPM microscope, USA. The images of the coating surface were obtained in scanning areas with a maximum dimension of $40 \mu \mathrm{m} \times 40 \mu \mathrm{m}$.

\section{Scratch Resistance and Tribological Properties}

The scratch resistance of the coatings and oxygen hardened Ti-6Al-4V substrate were investigated by micro-scratch tests using the Micro-Combi-Tester (MCT) device (CSM Instruments, Switzerland). The tests were performed using a Rockwell $\mathrm{C}$ indenter with a diamond tip radius of $200 \mu \mathrm{m}$. The scratch length of 5 $\mathrm{mm}$ and an indenter displacement rate of $5 \mathrm{~mm} / \mathrm{min}$ were set. Along the scratch length, the applied load was increased linearly from 0.03 to $30 \mathrm{~N}$. The critical loads $\mathrm{L}_{\mathrm{c} 1}$ and $\mathrm{L}_{\mathrm{c} 2}$, corresponding to cohesive cracks and adhesive failure, respectively, were determined from light microscopy (LM) observations, acoustic emission and friction force signals. The coating thickness was measured by contact profilometry using the MCT. The $15 \mathrm{~mm}$ traversing length started in the baseline area and finished on the coating surface.

A ball-on-disk apparatus, made in the Institute for Sustainable Technologies-National Research Institute, Poland, was used to investigate the friction and wear properties of the coated, oxygen hardened and baseline alloy. The tests were carried out during sliding in dry contact with alumina balls of $6 \mathrm{~mm}$ in diameter at ambient conditions set as: $22 \pm 1{ }^{\circ} \mathrm{C}$ RT and $50 \pm 5$ pct relative humidity. Experiments were conducted with the following test parameters: $5 \mathrm{~N}$ normal load, $140 \mathrm{rpm}$ rotation speed, $3 \mathrm{~mm}$ radius of the wear track and sliding distance of $2000 \mathrm{~m}$. The specific wear rate $W_{\mathrm{v}}$ $\left(\mathrm{mm}^{3} / \mathrm{Nm}\right)$ of the tested materials, calculated as a wear volume of the coating obtained from the cross-sectional area of the wear track $\left(\mathrm{mm}^{3}\right)$ divided by the applied normal load $(\mathrm{N})$ and the sliding distance $(\mathrm{m})$, was determined.

\section{E. Electrochemical Corrosion Resistance}

The open circuit potential (OCP), electrochemical polarization and electrochemical impedance spectroscopy (EIS) studies of the samples were carried out using an Autolab PGSTAT302N potentiostat, the Netherlands. The reference was a saturated calomel electrode and a platinum plate was used as the counter electrode. $\mathrm{NaCl}$ (3.5 wt pct) solution was used as the electrolyte for the corrosion study. Measurements were performed in aerated solutions at a temperature of 25 ${ }^{\circ} \mathrm{C}$. The polarization test was performed at a scan rate of $1 \mathrm{mV} / \mathrm{s}$ from -1.3 to $+1.5 \mathrm{~V}$. For the EIS measurements, the amplitude was $10 \mathrm{mV}$ and the frequency was from $10^{5}$ to $10^{-3} \mathrm{~Hz}$. The EIS data were fitted using the ZView software. Minimizing errors was performed using the chi-squared criteria for fitting the experimental data of the EIS. 


\section{RESULTS AND DISCUSSION}

\section{A. EPD of Coatings}

The particles used for coating deposition were investigated with SEM and TEM. SEM observation reveled that PEEK708 particles exhibited an irregular or globular shape with sizes (equivalent circle diameter, ECD) up to $10 \mu \mathrm{m}$. The XRD investigation of PEEK performed in our previous study ${ }^{[38]}$ showed an amorphous structure. TiN nanocrystalline particles (face centered cubic, fcc) exhibited a spherical and irregular shape with a diameter in the range of 2 to $75 \mathrm{~nm}$ (Figure 1).

Zeta potential of particles in pure ethanol and in the dispersion medium consisting of ethanol and colloidal solutions of chitosan was measured as a function of $\mathrm{pH}$. Both PEEK 708 micro particles and TiN nanoparticles exhibited negative ZP in ethanol for all the investigated $\mathrm{pH}$ range of 3.0 to 11.5 (Figure 2(a)). It was observed that the ZP for both types of particles was highly unstable. The highest value was measured in the basic suspension at $\mathrm{pH} 9.5$ and equaled $-32.2 \pm 1.2 \mathrm{mV}$ and $-36.9 \pm 1.5 \mathrm{mV}$ for PEEK708 and TiN, respectively.
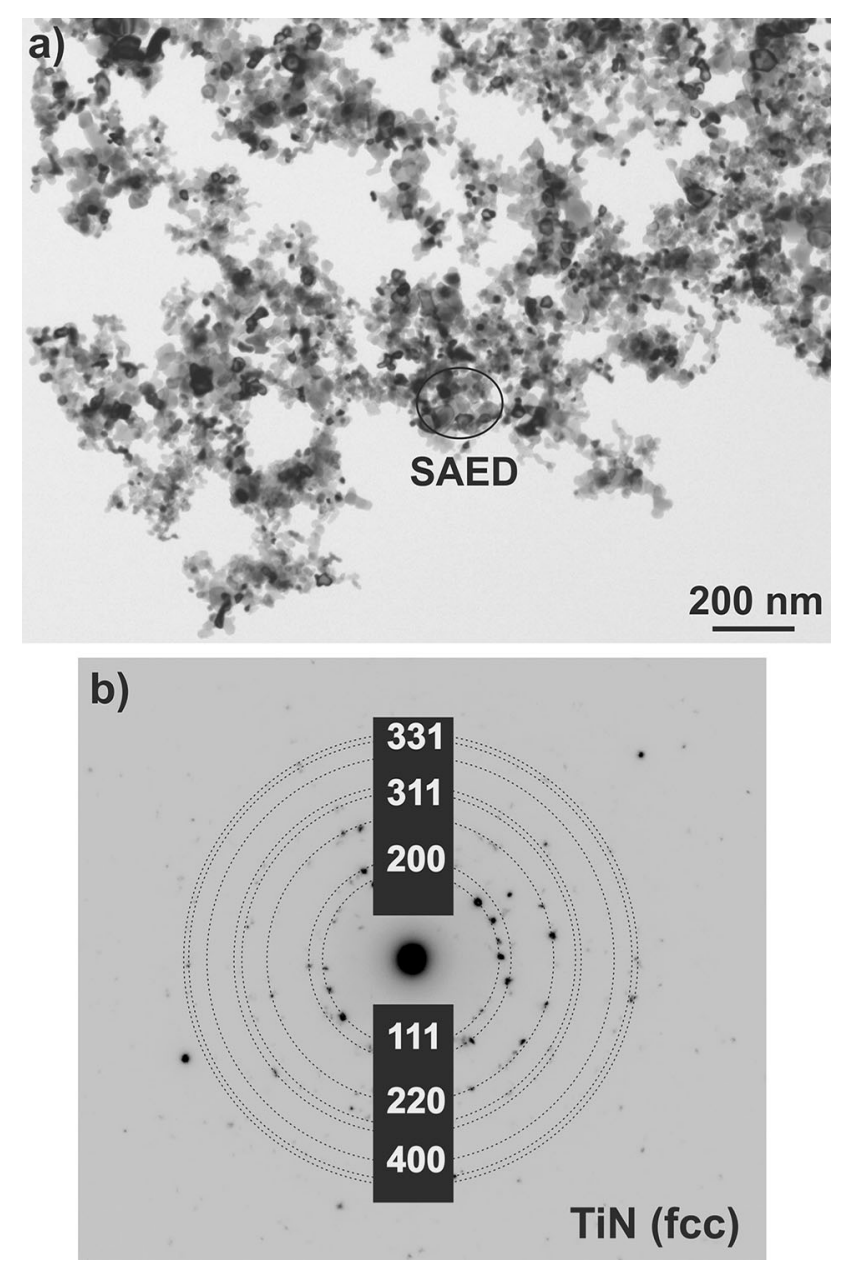

Fig. 1-TiN NPs $(a)$ and SAED pattern taken from the area marked in (a) and its identification as TiN (fcc) (b), TEM.
The addition of chitosan polyelectrolyte to ethanol changed the surface charge of particles from negative to positive. The ZP of PEEK 708 and TiN particles in the medium consisting of ethanol and colloidal solutions of chitosan exhibited positive zeta potential in the entire range of pH 3.0 to 5.5 (Figure 2(b)). In this case, the $\mathrm{ZP}$ of PEEK708 and TiN was much more stable. The highest value of $\mathrm{ZP}$, equal to $15.0 \pm 0.5$ and $17.7 \pm 0.6$ $\mathrm{mV}$ for PEEK 708 and TiN particles, respectively, was determined for suspensions with a $\mathrm{pH}$ equal to 4.0.

Thus, the suspensions with the $\mathrm{pH} 7.93$ and $\mathrm{pH} 4.36$ containing $1.50 \mathrm{~g}$ of PEEK 708 and $0.02 \mathrm{~g}$ of TiN in a dispersion medium composed of pure ethanol $(50 \mathrm{~mL})$ as well as in a medium consisting of $37.5 \mathrm{~mL}$ of ethanol and $12.5 \mathrm{~mL}$ of chitosan polyelectrolyte were selected for the coating deposition. It was observed that, in the case of EPD from pure alcohol, regardless of the deposition parameters, voltages, time and stirring, the suspension was not stable and we did not receive any deposition. The large PEEK particles had a tendency to form agglomerates and rapid sedimentation of particles in the suspension could be observed with the naked eye.

In contrast, during deposition from the suspension containing chitosan polyelectrolyte, the particle deposition was observed in a wide range of voltages of 60 to $120 \mathrm{~V}$. The highest macroscopic uniformity of the coatings was found for the voltage of $90 \mathrm{~V}$. The coatings deposited at voltages below $90 \mathrm{~V}$ were relatively thin, not homogeneous, and the particles were not uniformly distributed on the substrate surface. Meanwhile, the coatings deposited at voltages above $90 \mathrm{~V}$ were thick and not homogeneous in thickness, especially on the edges of the samples.

To describe the co-deposition mechanism of particles, TEM investigation of two types of suspensions was performed. The investigation of the pure ethanol-based suspension indicated electrostatic interaction between both types of particles. Agglomerates of the TiN NPs were adsorbed to PEEK micro particles, forming composite particles in the suspension (Figure 3(a)). In the case of the suspension containing the addition of chitosan polyelectrolyte, the TEM observations revealed the adsorption of chitosan molecules and chains to PEEK708 particles and to TiN NPs (Figure 3(b)). Thus, as shown by ZP measurements (Figure 2), cationic chitosan changes the surface charge of both types of particles and, as shown by TEM investigation, its molecules and chains prepared by protonation in the aqueous acetic acid solution adsorb to both types of particles and provide electrosteric stabilization of the suspension. This prevents the sedimentation of PEEK micro particles in the suspension and contributes to the co-deposition of both types of particles onto the titanium alloy substrate. The complex chitosan/PEEK and chitosan/TiN migrate towards the cathode under the influence of an electric field due to the positive $\mathrm{ZP}$, as shown schematically in Figure 4. The same mechanism of deposition was indicated in our previous work on the co-deposition of amorphous $\mathrm{Si}_{3} \mathrm{~N}_{4}$ nanoparticles and PEEK704 micro particles. ${ }^{[35]}$ 


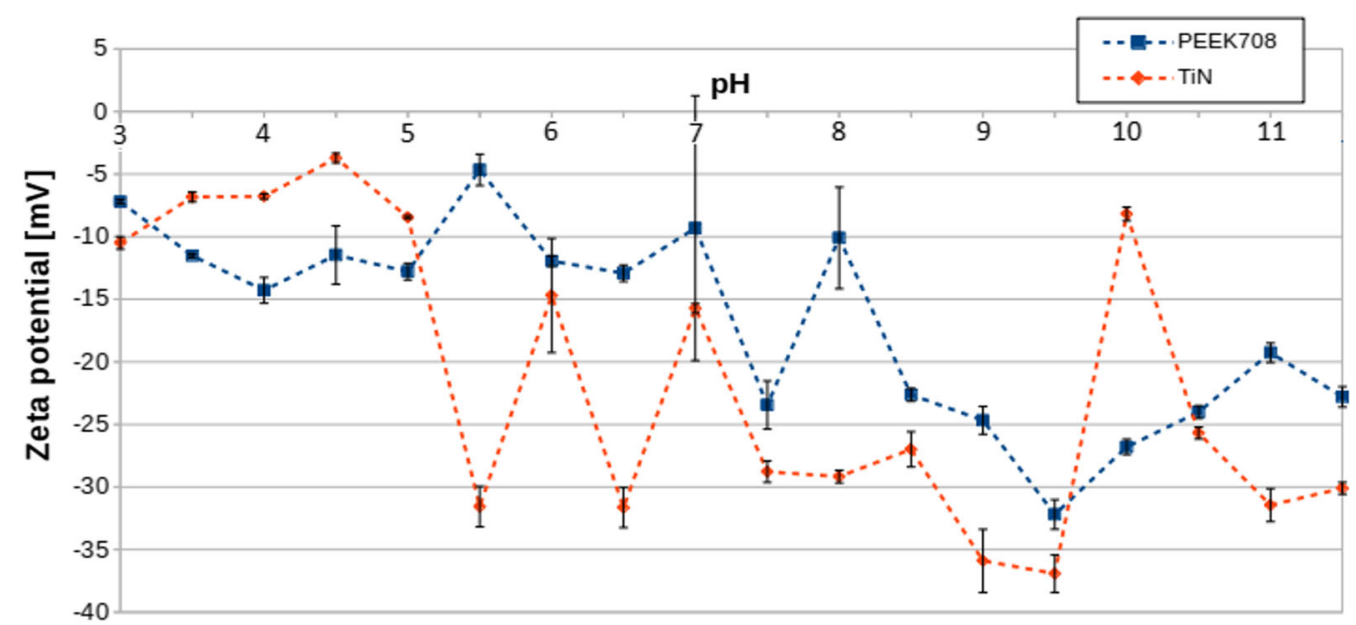

(a)

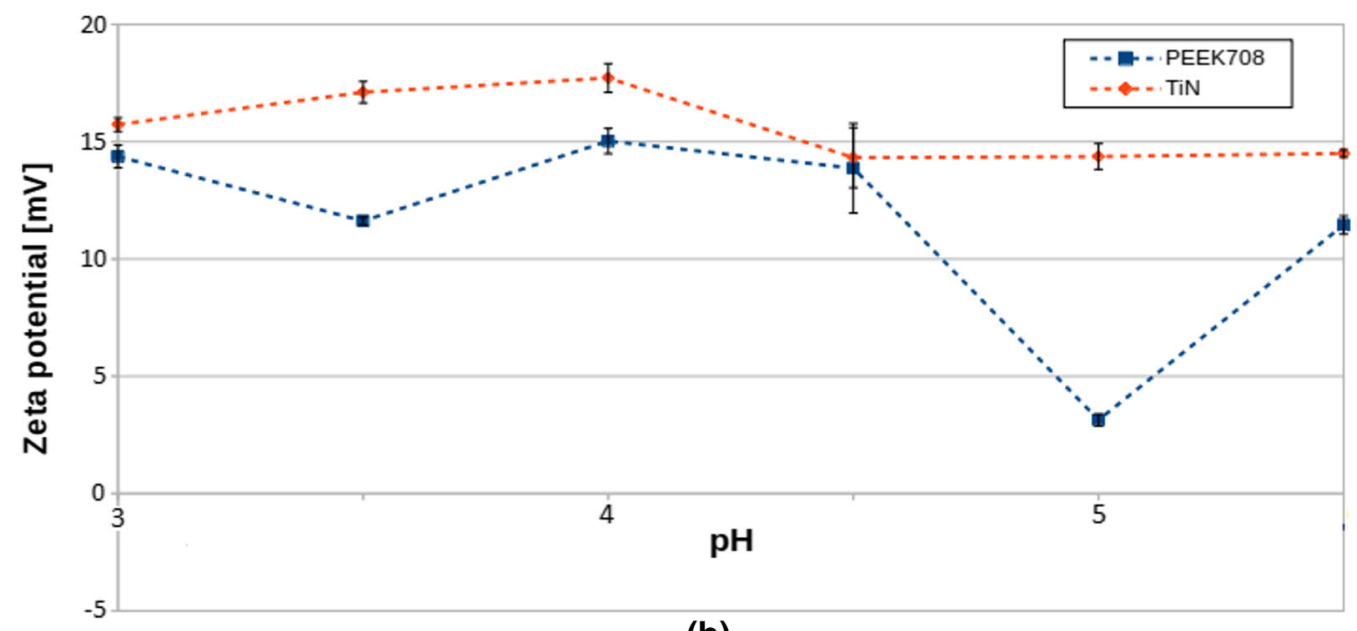

(b)

Fig. 2-Zeta potential of PEEK 708 and TiN particles as a function of $\mathrm{pH}$ in pure ethanol $(a)$ and in dispersion medium containing ethanol and 25 vol pct chitosan polyelectrolyte $(b)$.

\section{B. Coating Microstructure and Surface Topography}

The as-deposited coating exhibited a uniform distribution of PEEK 708 micro particles with TiN nanoparticles adsorbed onto the titanium alloy substrate (Figure 5). The post-heat treatment densified the coating by changing the morphology of PEEK from particles to a continuous coating matrix (Figure 6). The coating thickness was measured as approx. $120 \mu \mathrm{m}$. The structure of PEEK also changed from amorphous to semi-crystalline as a result of heat treatment.

The XRD pattern clearly showed the presence of four strong diffraction peaks coming from PEEK (Figure 7). Moreover, spherulites with a size of 3 to $7 \mu \mathrm{m}$ were observed on the coating surface (Figure 6). In contrast to $\mathrm{Si}_{3} \mathrm{~N}_{4} /$ PEEK 704 coatings,${ }^{[35]}$ in which an open micro porosity was present and no spherulites were observed on the surface of the coatings, mainly nano porosity associated with spherulite formation occurred in the TiN/PEEK 708 coatings. The occurrence of open pores, about $1 \mu \mathrm{m}$ in size, was rather sporadic. TEM investigation performed on lamellae cut from a cross-section of the coating confirmed the occurrence of separate nanoparticles and their agglomerates with a size up to $0.5 \mu \mathrm{m}$ in the polymer matrix (Figure 8).

Surface topography of the coatings was investigated by AFM. A representative image and the main surface roughness parameters are shown in Figures 9(a) and (b), respectively. It should be noted that the measured areas were relatively small and, in this case, the obtained roughness parameters may not be representative for the entire coating. Thus, the parameters were used only for qualitative comparison with the pure PEEK708 coating, for which the same measuring procedure was applied. It was found that the coating exhibited a high surface roughness, which was indicated mainly by the image surface area difference (ISAD, also called image area difference pct), the average roughness $(\mathrm{Ra})$, the mean square roughness $(\mathrm{Rq})$, and total roughness ( $\mathrm{Rt}$ or Rmax). The ISAD represents the difference between the image's three-dimensional surface area and its two-dimensional, footprint area, ${ }^{[39]}$ and for a perfect smooth surface it would be 0 pet. 

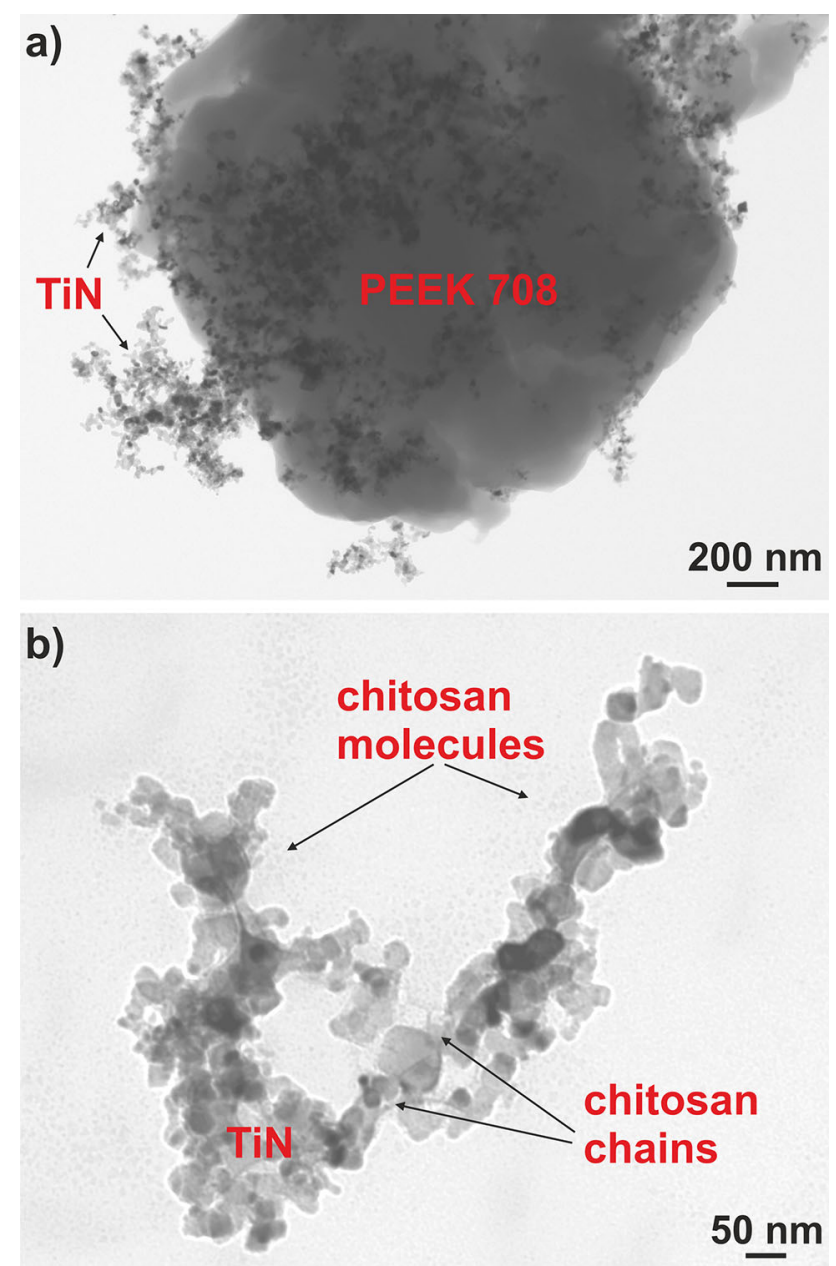

Fig. 3-TEM images of electrostatic interaction between the PEEK 708 particles and TiN NPs $(a)$ as well as TiN NPs with adsorbed chitosan molecules and chains $(b)$.

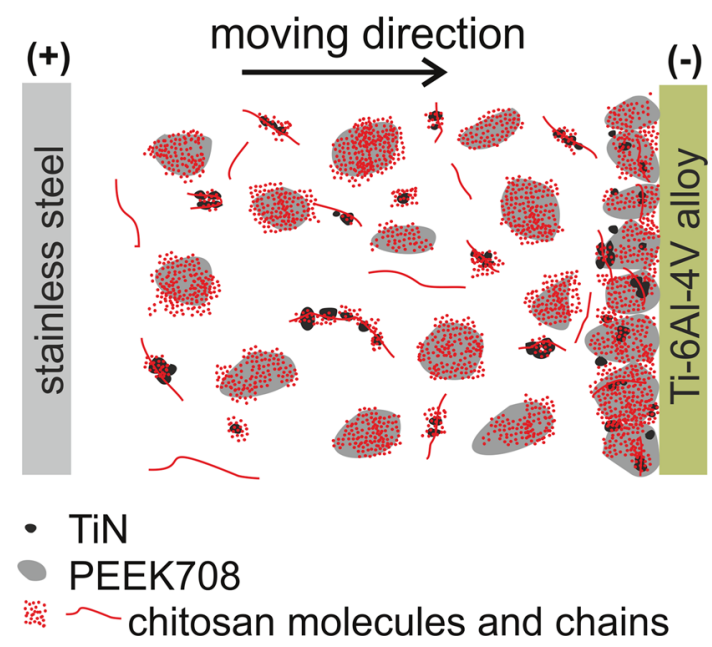

Fig. 4 -Schematic diagram showing the co-deposition mechanism of the TiN and PEEK 708 particles in the presence of chitosan.

In comparison to the surface roughness of the semi-crystalline pure PEEK 708 coating, ${ }^{[38]}$ the TiN/ PEEK 708 coating exhibited higher roughness, the ISAD

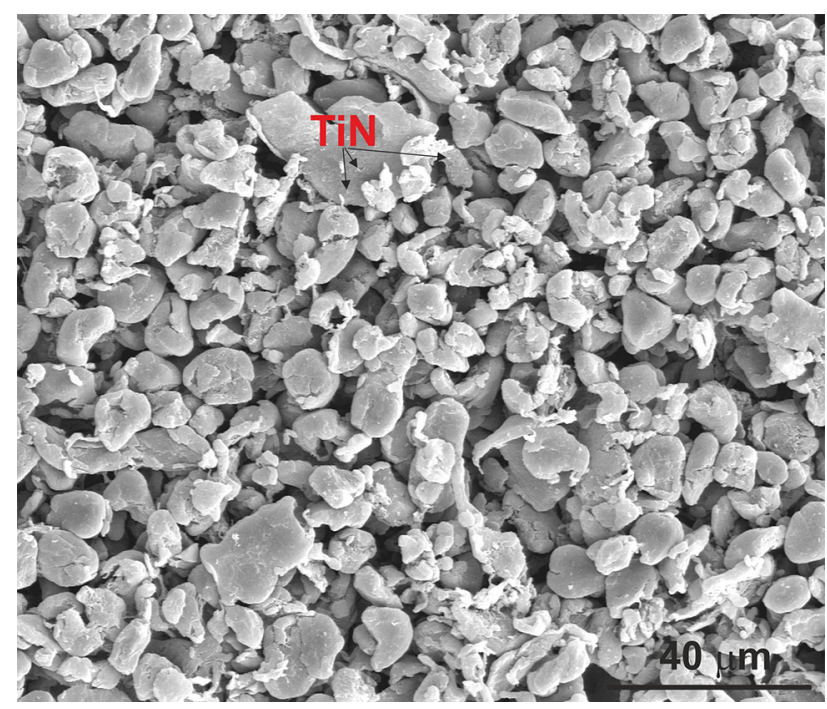

Fig. 5-Microstructure of the as-deposited TiN/PEEK708 coating, SEM secondary electron (SE) image.

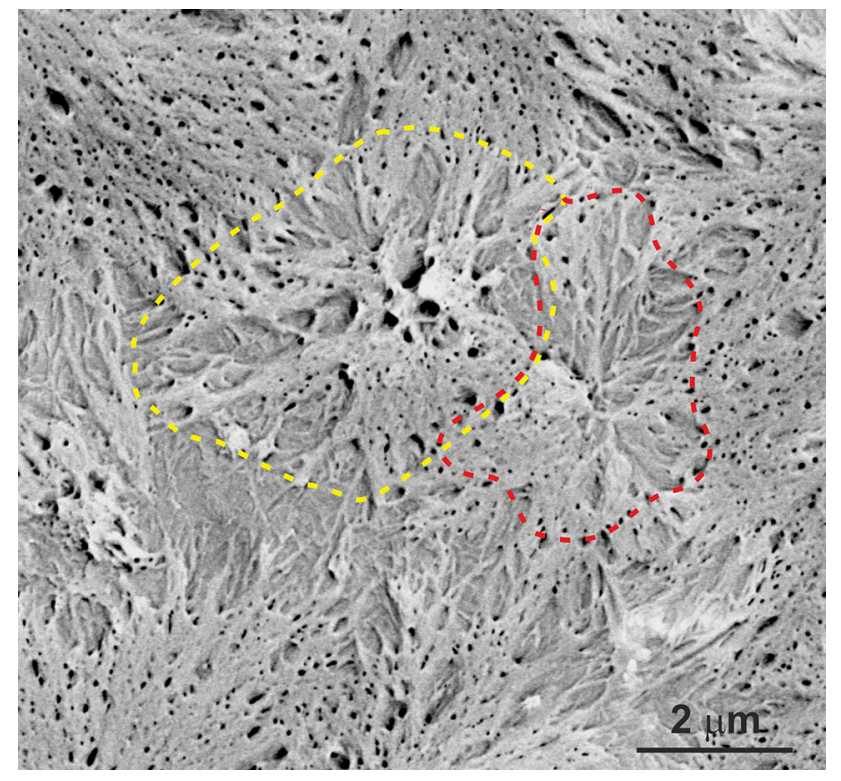

Fig. 6-Microstructure of the TiN/PEEK 708 coating after post EPD heat treatment, SEM image taken with a circular backscatter detector (CBS). Spherulites are marked by yellow and red circles.

was $3.40 \pm 0.01$ and $10.0 \pm 3.1 \mathrm{pct}, \mathrm{Ra}$ was $65 \pm 9$ and $82.7 \pm 13.0 \mathrm{~nm}$, and $\mathrm{Rq}$ was $86 \pm 11$ and $108.5 \pm 18.5$ $\mathrm{nm}$, respectively. In particular, the ISAD parameter was three times higher than that of the pure semi-crystalline PEEK 708 coating. This is a result of the present TiN nanoparticles, which probably inhibit the growth of spherulites during heat treatment, and therefore contribute to the increased surface roughness of the coating.

\section{Electrochemical Corrosion Resistance}

Figure 10(a) shows the evolution of open circuit potential for the baseline, oxygen hardened, and coated Ti-6Al-4V alloy. The results of these measurements 


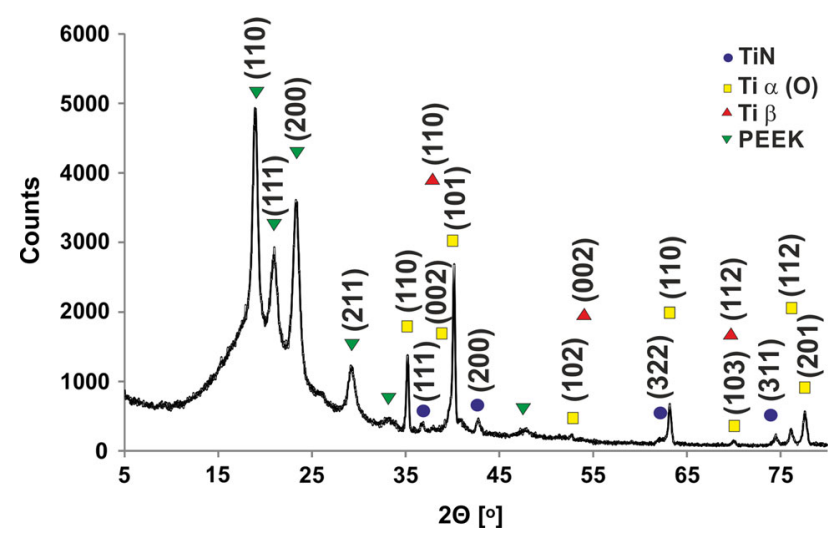

Fig. 7-XRD pattern of the TiN/PEEK708 coating on the oxygen hardened Ti-6Al-4V alloy after heat treatment.
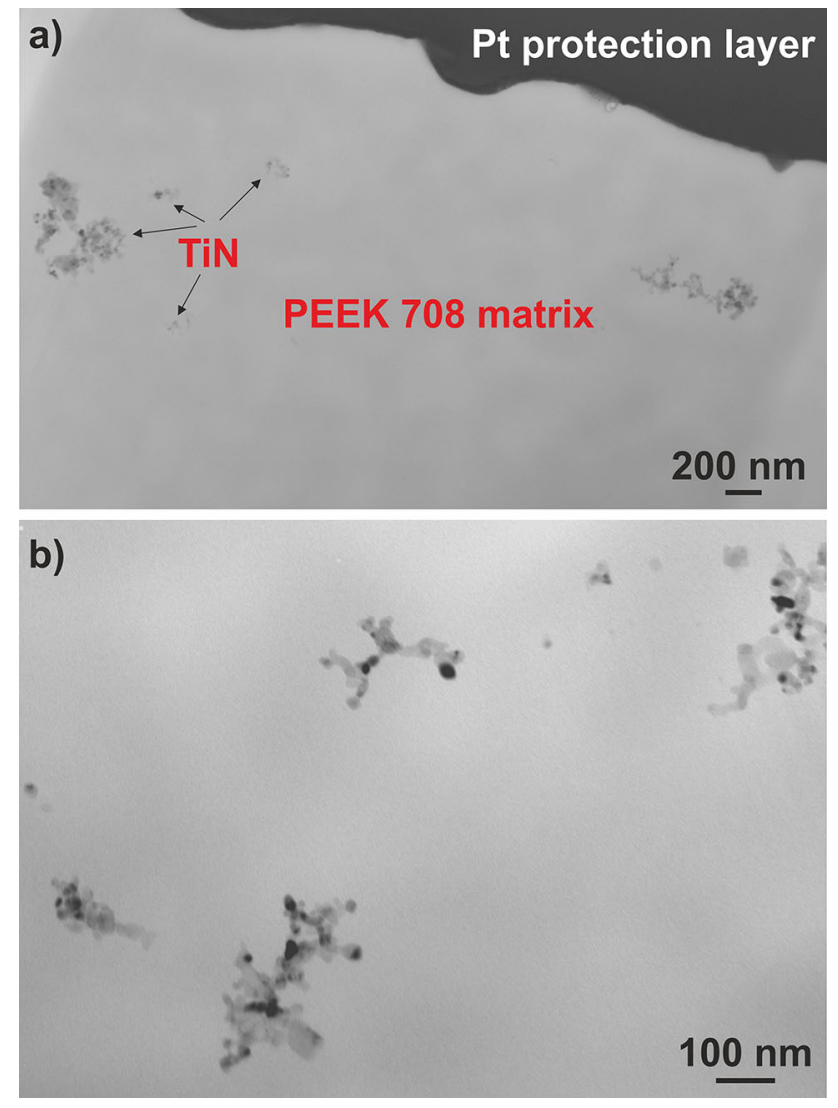

Fig. 8-TEM micrographs of the heat treated TiN/PEEK 708 coating taken from a cross-section area close to the coating surface $(a)$ and area at a distance of approx. $10 \mu \mathrm{m}$ from the surface $(b)$. FIB lamella.

show that the oxygen hardened alloy presents a more active potential (lower potential value equal $-0.21 \mathrm{~V}$ ) than the Ti-6Al-4V alloy, indicating that the substrate surface after oxygen hardening is more susceptible to corrosion. The potential value of the investigated samples was stable in time and equal to $0.32 \mathrm{~V}$ for the baseline alloy and about $-0.20 \mathrm{~V}$ for the oxygen hardened alloy. For the coated sample, it started at around $1.4 \mathrm{~V}$ and decreased to $0.30 \mathrm{~V}$ after around 4500

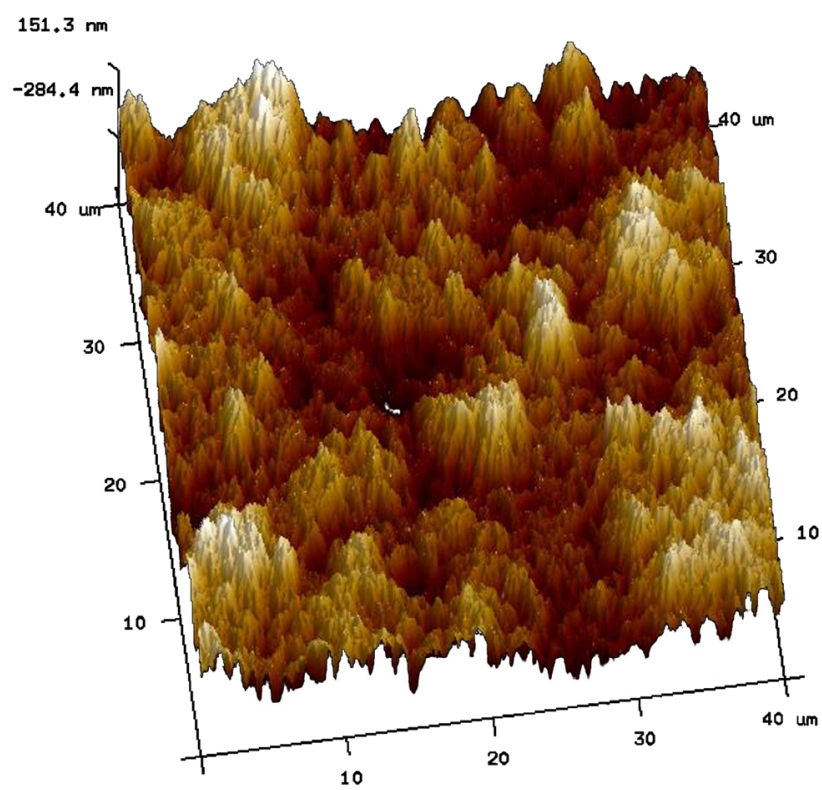

(a)

\begin{tabular}{|c|c|}
\hline Parameter & Value \\
\hline $\mathrm{R}_{\mathrm{a}}$ & $82.7 \pm 13.0 \mathrm{~nm}$ \\
\hline $\mathrm{R}_{\mathrm{q}}$ & $108.5 \pm 18.5 \mathrm{~nm}$ \\
\hline $\mathrm{R}_{\max }$ & $861.9 \pm 274.0 \mathrm{~nm}$ \\
\hline $\mathrm{ISAD}$ & $10.0 \pm 3.1 \%$ \\
\hline
\end{tabular}

(b)

Fig. 9-Typical image of surface topography of the heat treated TiN/PEEK 708 coating, AFM $(a)$ and selected parameters of its surface topography $(b)$.

seconds. Potentiodynamic polarization testing was conducted to gain further understanding of the corrosion properties of the investigated samples (Figure 10(b)). Because of the absence of linear regions, Tafel extrapolation is not applicable to interpret the electrochemical response. In such cases, the corrosion rate can be defined by the limiting current density which passes through the passivating film, thus becoming a measure of the film protective performance. ${ }^{[40]}$ The passive current density $\left(i_{\mathrm{p}}\right)$ was reduced from $32 \mu \mathrm{A} / \mathrm{cm}^{2}$ for the oxygen hardened sample to $5 \mu \mathrm{A} / \mathrm{cm}^{2}$ for the baseline alloy and $0.09 \mu \mathrm{A} / \mathrm{cm}^{2}$ for the coated one, while the corrosion potential $\left(E_{\text {corr }}\right)$ increased from $\sim-0.50 \mathrm{~V}$ for both, oxygen hardened and baseline, to $-0.30 \mathrm{~V}$ for the coated alloy. This shift in the polarization curve indicates improved corrosion resistance of the coated alloy as the coating acts as a protective layer.

Figures 11(a) and (b) show the EIS spectra presented as a Nyquist plot (Figure 11(a)) and a Bode plot (Figure 11(b)) of the baseline, oxygen hardened and coated alloy at the OCP in the sodium chloride solution. The equivalent circuits as shown in Figure 12 were used to fit the EIS data. For a baseline and oxygen hardened alloy, an experimental diagram was fitted considering the simplified Randles equivalent circuit (Figure 12(a)). It consists of a resistance R1 (electrolyte resistance) in 


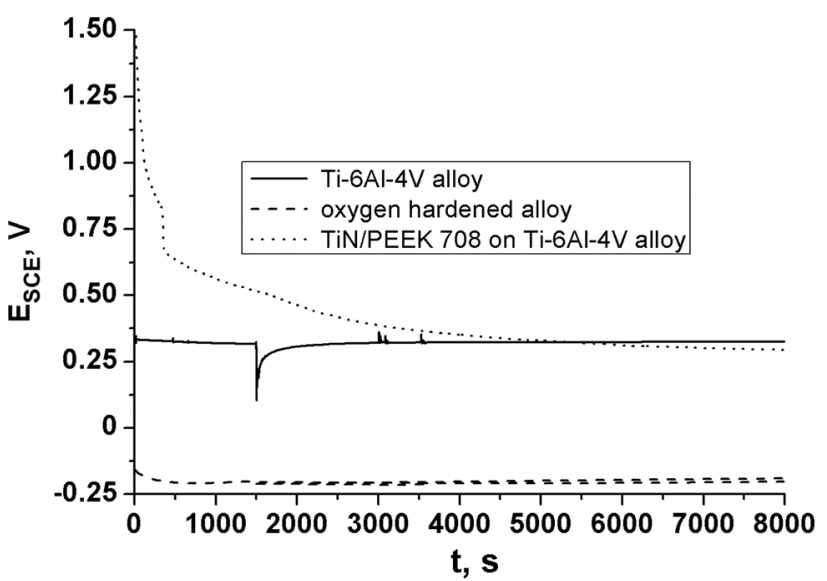

(a)

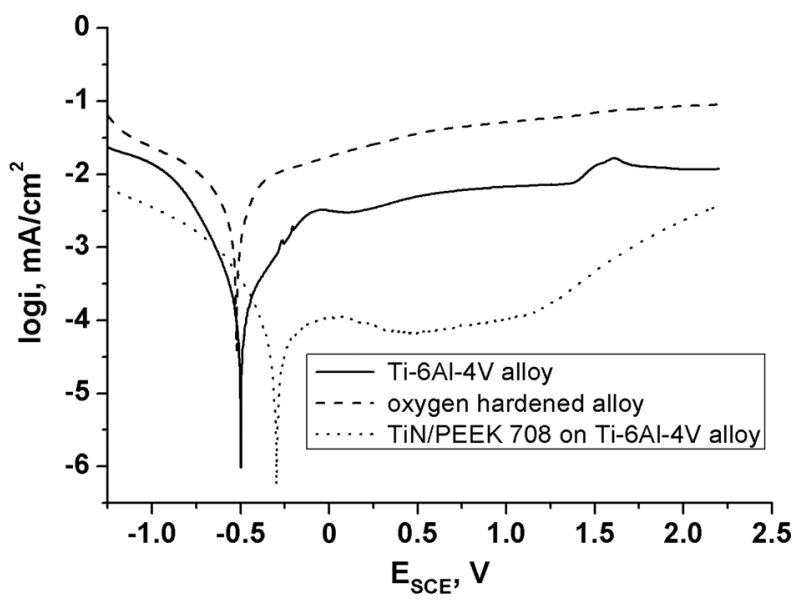

(b)

Fig. 10-Electrochemical measurements of the baseline, oxygen hardened and TiN/PEEK 708 coated Ti-6Al-4V alloy in $3.5 \mathrm{wt}$ pct $\mathrm{NaCl}$ solution at $25{ }^{\circ} \mathrm{C}$ : evolution of the corrosion potential vs time (a) and polarization curves at $1 \mathrm{mV} / \mathrm{s}(b)$.

series with the parallel combination of a constant phase element (CPE1) and a resistance R2 (polarization resistance). The R2 parameter is considered to include the contributions of the charge-transfer resistances, the oxide film resistance, and the migration of point defects mediating the growth of the passive film and dissolution of metal through it. A good fitting between the experimental and simulated results was achieved and the parameters are listed in Table I.

The baseline Ti-6Al-4V alloy had a slightly higher CPE-P value than the oxygen hardened one, which was the closest to the capacitance 1, typical of passive coatings. Simultaneously, the ohmic resistance (R2) of the baseline alloy was higher than that of the oxygen hardened alloy. The $\mathrm{Z}$ modulus in the Bode impedance plot in Figure 11(b) was comparable for both samples. This result was accordant with the OCP and polarization results and indicated that the baseline alloy had slightly better corrosion resistance than the oxygen hardened one.

To simulate the two time-constant responses observed in the impedance spectra of the TiN/PEEK 708 coated alloy, CPE-1 in parallel with a resistance (R2) were used.

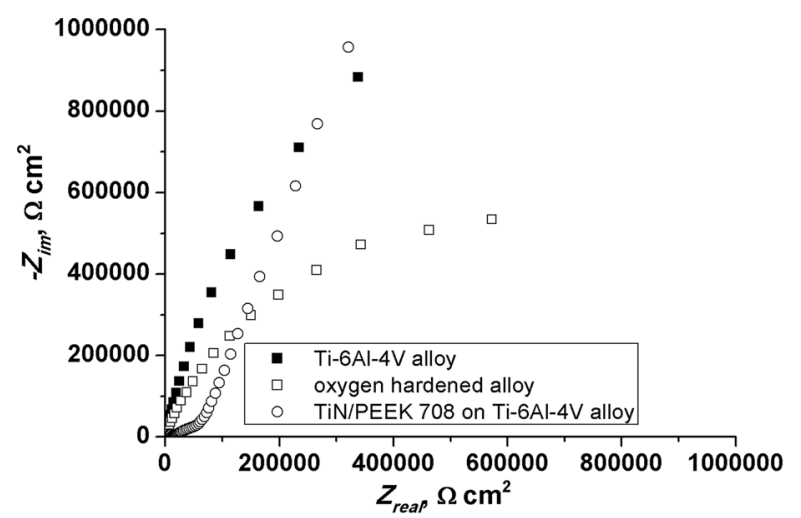

(a)

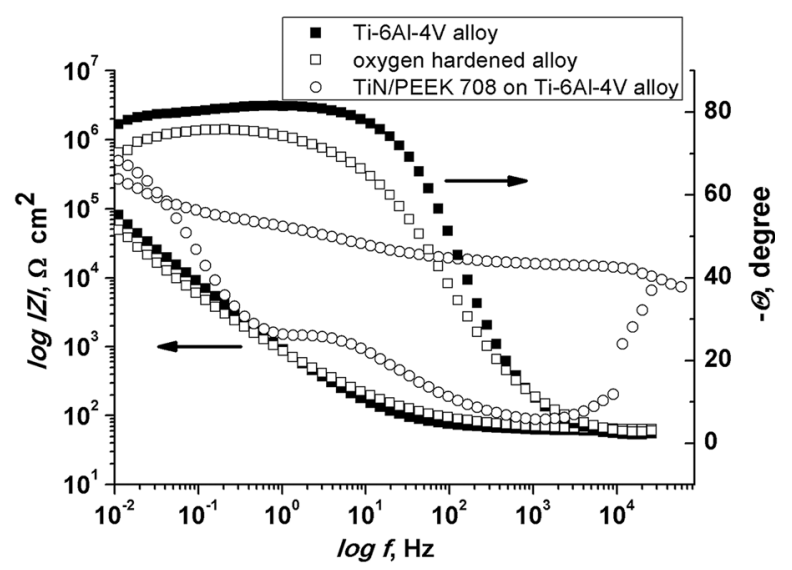

(b)

Fig. 11-Electrochemical impedance curves of the baseline, oxygen hardened and TiN/PEEK 708 coated Ti-6Al-4V alloy in $3.5 \mathrm{wt}$ pet $\mathrm{NaCl}$ solution: Nyquist impedance plot $(a)$, Bode impedance plot (b).

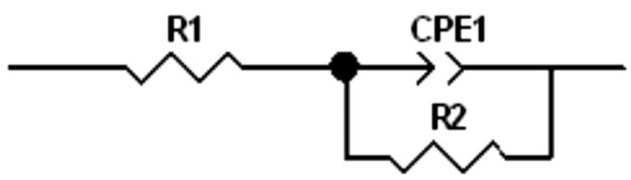

(a)

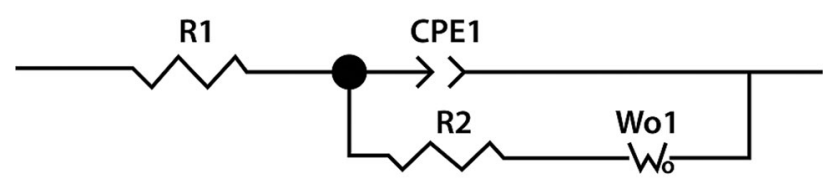

(b)

Fig. 12-Equivalent circuit used for fitting EIS data of the baseline and oxygen hardened Ti-6Al-4V $(a)$ and TiN/PEEK 708 coated alloy (b).

Both components were associated with the response of the barrier layer, which is connected in series with a diffusive component (W) associated with the diffusion process in the layer (Figure 12(b)). According to the values from the equivalent circuit shown in Table $\mathrm{I}$, the CPE1-P value for the TiN/PEEK708 coated alloy equaled 1 , which is equivalent to a capacitor (CPE parameter is used to compensate for coating 
Table I. EIS Fitting Results Obtained from EIS Data

Samples

Elements of the Electric

Equivalent Circuits

$\mathrm{R}_{1}\left(\Omega^{*} \mathrm{~cm}^{2}\right)$

CPE1-T $\left(\mathrm{Fs}^{\mathrm{n}-1} \mathrm{~cm}^{-2}\right)$

CPE1-P

$\mathrm{R}_{2}\left(\Omega * \mathrm{~cm}^{2}\right)$

CPE2-T $\left(\mathrm{Fs}^{\mathrm{n}-1} \mathrm{~cm}^{-2}\right)$

CPE2-P

$\chi^{2}$

\section{Ti-6Al-4V}

$60.45 \pm 0.1999$

$3.0272 \times 10^{-5} \pm 6.9365 \times 10^{-8}$

$0.91 \pm 0.0006$

$4.2551 \times 10^{6} \pm 72812$

-

$\overline{0.001}$
Oxygen Hardened Ti-6Al-4V

$66.58 \pm 0.58062$

$6.4642 \times 10^{-5} \pm 3.9854 \times 10^{-7}$

$0.83 \pm 0.0017179$

$1.5868 \times 10^{6} \pm 82965$

-

$\overline{0.006}$
TiN/PEEK 708 Coating on Ti-6Al-4V
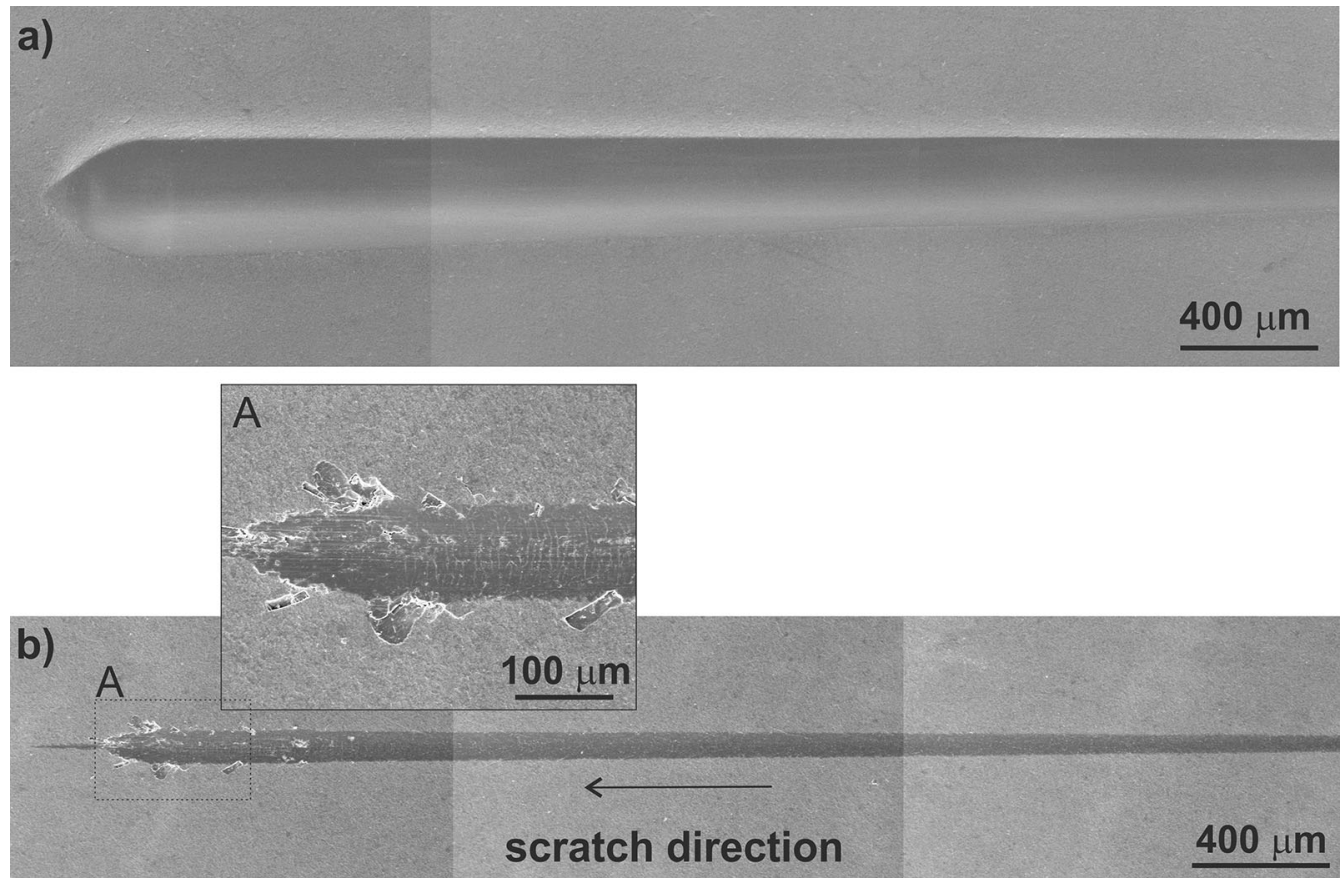

Fig. 13-Typical SEM secondary electron image of the scratch track in the TiN/PEEK 708 coating on the oxygen hardened Ti-6Al-4V alloy (a) and in the oxygen hardened alloy $(b)$ at the load of $30 \mathrm{~N}$. Magnified details of the area marked with the letter A are shown at the top of the figure.

non-homogeneity). The constant phase element (CPE-2) was used in this situation instead of the Warburg element $(W)$. However, the open system investigated in Figures 11(a) and (b) shows a similarly marked deviation from the standard Warburg model. Two time-constants are clearly observed (Figure 11(b)), the first one at the frequency range of $10^{5}$ to $\sim 10^{0} \mathrm{~Hz}$ is related to the response of the barrier layer at the bottom of the anodic structures (nanoporous), and the second time-constant described at $\sim 10^{0}$ to $10^{-2} \mathrm{~Hz}$ is associated with an ion diffusion process by a passive layer (CPE2-P = 0.41). ${ }^{[41,42]} \mathrm{Z}$ modulus (Figure 11(b)) values indicate that the TiN/PEEK 708 coated alloy has higher impedances at all frequencies than the baseline and oxygen hardened samples. These results indicate a better corrosion resistance than the coated alloy compared to the other ones.

\section{Scratch Resistance of the Coatings and Tribological Properties of the Baseline and Coated Alloy}

The heat treated TiN/PEEK708 coatings exhibited very good scratch resistance. During the micro-scratch tests, no cohesive cracks and adhesive failure were observed along the scratch track for the maximum load of the equipment used, e.g., $30 \mathrm{~N}$ (Figure 13(a)). Contact with the rigid spherical indenter caused only a plastic deformation of the coating and a large pile-up near the end of the scratch indicative of the coating's soft nature. In comparison with the coated alloy the 


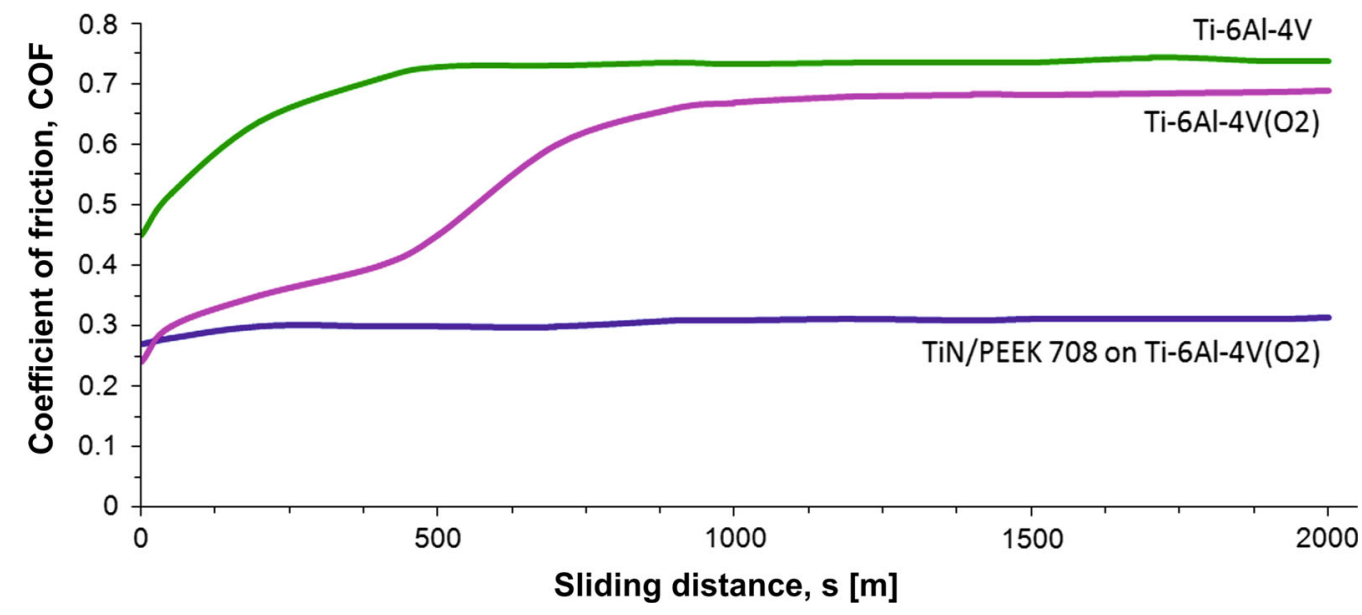

Fig. 14 -Evolution of the coefficient of friction $v s$ sliding distance for the baseline and oxygen hardened Ti-6Al-4V alloy and TiN/PEEK708 coated oxygen hardened alloy.

contrary mechanism of failure of the oxygen hardened Ti-6Al-4V alloy was observed. The diffusion layer enriched with oxygen of the treated titanium alloy is much harder than the coating but is therefore more brittle. First cohesive cracks of the layer were occurred at a load of $\mathrm{L}_{\mathrm{Cl}}=18 \mathrm{~N}$. Load increase caused the progressive failure of the layer in the form of the conformal buckling cracks and chipping of the layer at $28 \mathrm{~N}$ (Figure 13(b)). Pile-up was not observed at the end of the scratch, due to the harder and stiffer nature of the layer (area $A$ in the Figure 13(b)) in comparison with the coating.

The mean coefficient of friction of the TiN/PEEK 708 coated alloy in contact with an alumina ball during dry sliding contact was below 0.30 and was relatively stable (Figure 14). This value is close to the COF of the pure PEEK 708 coated alloy, equal to 0.27 , obtained previously in the same test setup. ${ }^{[38]}$ In comparison, the COFs of the uncoated alloys were high and equalled 0.65 and 0.70 .

It was found that the TiN/PEEK708 coating significantly increased the wear resistance of the alloy. The wear rate for the TiN/PEEK708 coated alloy was $(1.1 \pm$ $0.1) \times 10^{-6} \mathrm{~mm}^{3} / \mathrm{Nm}$ and was smaller than for the PEEK708 coated alloy $(3.19 \pm 0.21) \times 10^{-6} \mathrm{~mm}^{3} /$ $\mathrm{Nm}^{[38]}$ and for the oxygen hardened alloy (79 \pm 11) $\times 10^{-6} \mathrm{~mm}^{3} / \mathrm{Nm}$, as well as significantly smaller than for the uncoated Ti-6Al-4V alloy $(720 \pm 17) \times 10^{-6}$ $\mathrm{mm}^{3} / \mathrm{Nm}$. The wear mechanism of the composite coating was mainly abrasive. In the wear track many abrasive scratches were found in accordance with the sliding direction (Figure 15). The wear products of the coating were occurred outside the wear track on both sides of the groove and in a contact zone. Plastic deformation in the frictional contact of the polymer coating was not found. The wear of the uncoated oxygen hardened titanium alloy was also abrasive. However, the wear intensity of this alloy was many times higher compared to the coated alloy, despite the significantly lower hardness of the polymer coating. Hard wear products of the hardened alloy present in the

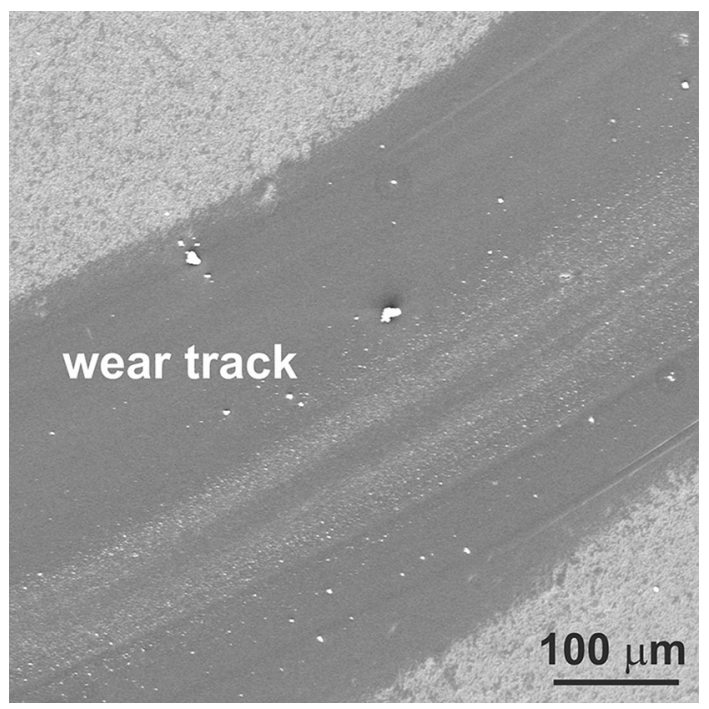

Fig. 15-SEM image of the wear track in the TiN/PEEK708 coating on oxygen hardened Ti-6Al-4V alloy after dry friction contact with $\mathrm{Al}_{2} \mathrm{O}_{3}$ ball.

sliding contact intensified the alloy wear and caused an unstable cooperation.

\section{CONCLUSIONS}

1. The addition of chitosan polyelectrolyte to the ethanol-based suspensions enabled homogeneous co-deposition of polymer PEEK 708 micro particles and TiN nanoparticles onto the oxygen hardened Ti-6Al-4V alloy.

2. The post-heat treatment densified the coatings and changed the polymer structure from amorphous to semi-crystalline. TiN separate nanoparticles and their agglomerates with sizes up to $0.5 \mu \mathrm{m}$ were embedded into the PEEK 708 matrix. In comparison with pure PEEK 708 coatings, ${ }^{[38]}$ the TiN/PEEK708 coatings 
exhibited three times higher surface roughness due to the presence of TiN particles, which inhibited the growth of spherulites during heat treatment.

3. The oxygen hardened alloy had slightly inferior corrosion resistance parameters compared to the baseline alloy. The TiN/PEEK 708 coating improved the corrosion resistance of the oxygen hardened Ti-6Al-4V alloy in the $\mathrm{NaCl}$ aqueous solution.

4. The TiN/PEEK 708 coatings decreased the friction coefficient of the alloy from 0.70 for the baseline alloy and 0.65 for the oxygen hardened alloy to 0.30 . They also significantly increased the wear resistance of the alloy during dry sliding contact with an alumina ball at RT. The wear rate of the coated oxygen hardened alloy was 70 times lower than that of the oxygen hardened alloy and 650 times lower than that of the baseline one.

\section{ACKNOWLEDGMENTS}

The study was supported by AGH-UST (project no. 16.16.110.663). The authors appreciate the valuable contributions of Dr. Ł. Cieniek (AGH University of Science and Technology) to SEM investigation, Dr. Habil. A. Kopia (AGH-UST) to XRD investigation, A. Fiołek, MSc (AGH-UST) to AFM, and Dr. W. Pawlak (Lodz University of Technology) for glow discharge plasma thermal oxidation treatment.

\section{OPEN ACCESS}

This article is distributed under the terms of the Creative Commons Attribution 4.0 International License (http://creativecommons.org/licenses/by/4.0/), which permits unrestricted use, distribution, and reproduction in any medium, provided you give appropriate credit to the original author(s) and the source, provide a link to the Creative Commons license, and indicate if changes were made.

\section{REFERENCES}

1. Titanium and Titanium Alloys, 2 nd ed., C Leyens, and M Peters, eds., Titanium and Titanium Alloys, Wiley-VCH Verlag $\mathrm{GmbH} \& \mathrm{Co}$. KGaA, Weinheim, 2003, pp. 393-465.

2. P Singha, H Pungotra, and NS Kalsi: Mater. Today Proc., 2017, vol. 4 , pp. 8971-82.

3. J. Sieniawski, W. Ziaja, K. Kubiak, and M. Motyka, Microstructure and Mechanical Properties of High Strength TwoPhase Titanium Alloys, Chapter 4, INTECH 2013, pp. 70-79.

4. KG Budinski: Wear, 1991, vol. 151, pp. 203-217.

5. H. Dong (ed.): Surface Engineering of Light Alloys Aluminium, Magnesium and Titanium Alloys, Woodhead Publishing Series in Metals and Surface Engineering, 2010, pp. 58-80.

6. T Moskalewicz, B Wendler, and A Czyrska-Filemonowicz: Mater. Charact., 2010, vol. 61, pp. 959-68.

7. Q Gao, H Yan, Y Qin, P Zhang, J Guo, Z Chen, and Z Yu: Opt. Laser Technol., 2019, vol. 113, pp. 182-91.

8. T Moskalewicz, B Wendler, S Zimowski, B Dubiel, and A Czyrska-Filemonowicz: Surf. Coat. Technol., 2010, vol. 205, pp. $2668-77$.
9. X Hong, Y Tan, X Wang, T Xu, and L Gao: Surf. Coat. Technol., 2016, vol. 305, pp. 67-75.

10. T Moskalewicz, W Grogger, and A Czyrska-Filemonowicz: $J$. Microsc., 2006, vol. 223, pp. 195-99.

11. I Corni, M Cannio, M Romagnoli, and AR Boccaccini: Mater. Res. Bull., 2009, vol. 44, pp. 1494-1501.

12. I Corni, N Neumann, S Novak, K König, P Veronesi, Q Chen, MP Ryan, and AR Boccaccini: Surf. Coat. Technol., 2009, vol. 203, pp. 1349-59.

13. MA Ur Rehman, FE Bastan, B Haider, and AR Boccaccini: Mater. Des., 2017, vol. 130, pp. 223-30.

14. S Seuss, T Subhani, MY Kang, K Okudaira, IE Aguilar Ventura, and AR Boccaccini: Key Eng. Mater., 2012, vol. 507, pp. 127-33.

15. D Luo and I Zhitomirsky: J. Electrochem. Soc., 2015, vol. 162, pp. D3057-62.

16. G Zhang, H Liao, H Li, C Mateus, JM Bordes, and C Coddet: Wear, 2006, vol. 260, pp. 594-600.

17. T Palathai, J Tharajak, and N Sombatsompop: Mater. Sci. Eng. A, 2008, vol. 485, pp. 66-73.

18. K Patel, CS Doyle, D Yonekura, and BJ James: Surf. Coat. Technol., 2010, vol. 204, pp. 3567-72.

19. G Zhang, H Liao, H Yu, S Costil, SG Mhaisalkar, JM Bordes, and C Coddet: Surf. Coat. Technol., 2006, vol. 201, pp. 243-49.

20. JA Puertolas, M Castro, JA Morris, R Ríos, and A Anson-Casaos: Carbon, 2019, vol. 141, pp. 107-22.

21. D Kumar, T Rajmohan, and S Venkatachalapathi: Mater. Today Proc., 2018, vol. 5, pp. 14583-89.

22. RS Virk, MAU Rehman, and AR Boccaccini: ECS Trans., 2018, vol. 82, pp. 89-95.

23. EZ Li, WL Guo, HD Wang, BS Xu, and XT Liu: Phys. Procedia, 2013, vol. 50, pp. 453-60

24. JP Davim and R Cardoso: Wear, 2009, vol. 266, pp. 795-99.

25. AR Boccaccini, C Peters, JA Roether, D Eifler, SK Misra, and EJ Minay: J. Mater. Sci., 2006, vol. 41, pp. 8152-59.

26. T Moskalewicz, S Seuss, and AR Boccaccini: Appl. Surf. Sci., 2013, vol. 273, pp. 62-67.

27. FE Bastan, MA Ur Rehman, YY Avcu, E Avcu, and AR Boccaccini: Colloids Surf. B, 2018, vol. 169, pp. 176-82.

28. G Zhang, AK Schlarb, S Tria, and O Elkedim: Compos. Sci. Technol., 2008, vol. 68, pp. 3073-80.

29. M Hedayati, M Salehi, R Bagheri, M Panjepour, and F Naeimi: Prog. Org. Coat., 2012, vol. 74, pp. 50-58.

30. G Zhang, S Guessasma, H Liao, H Coddet, and J-M Bordes: Surf. Coat. Technol., 2006, vol. 200, pp. 2610-17.

31. G Zhang, H Liao, H Yu, V Ji, W Huang, SG Mhaisalkar, and C Coddet: Surf. Coat. Technol., 2006, vol. 200, pp. 6690-95.

32. A Sak, T Moskalewicz, S Zimowski, Ł Cieniek, B Dubiel, A Radziszewska, M Kot, and A Łukaszczyk: Mater. Sci. Eng. C, 2016, vol. 63, pp. 52-61.

33. T Moskalewicz, A Zych, A Łukaszczyk, K Cholewa-Kowalska, A Kruk, B Dubiel, A Radziszewska, K Berent, and M Gajewska: Metall. Mater. Trans. A, 2017, vol. 48A, pp. 2660-73.

34. T Moskalewicz, S Zimowski, A Zych, A Lukaszczyk, K Reczyńska, and E Pamuła: J. Electrochem. Soc., 2018, vol. 165, pp. D116-28.

35. T Moskalewicz, A Zych, A Kruk, A Kopia, S Zimowski, M Sitarz, and $\longleftarrow$ Cieniek: Surf. Coat. Technol., 2018, vol. 350, pp. 633-47.

36. T Moskalewicz, A Kruk, M Sitarz, and A Kopia: J. Electrochem. Soc., 2019, vol. 166, pp. D151-61.

37. RG Duan, G Roebben, and C Sarbu: Key Eng. Mater., 2002, vols. 206-213, pp. 1181-84.

38. A Kruk, S Zimowski, A Łukaszczyk, Ł Cieniek, and T Moskalewicz: Prog. Org. Coat., 2019, vol. 133, pp. 180-90.

39. SE Oraby and AM Alaskari: Int. J. Mech. Aerosp. Ind. Mechatron. Manuf. Eng., 2010, vol. 4, pp. 977-88.

40. E Mc Cafferty and GK Hubler: J. Electrochem. Soc., 1978, vol. 125 , pp. $1892-93$

41. WF Cui, L Jin, and L Zhou: Mater. Sci. Eng. C, 2013, vol. 33, pp. $3775-79$.

42. LE Amato, DA López, PG Galliano, and SM Ceré: Mater. Lett., 2005, vol. 59, pp. 2026-31.

Publisher's Note Springer Nature remains neutral with regard to jurisdictional claims in published maps and institutional affiliations. 